\title{
Volatile Composition and Enantioselective Analysis of Chiral Terpenoids of Nine Fruit and Vegetable Fibres Resulting from Juice Industry By-Products
}

\author{
Alexis Marsol-Vall, ${ }^{1}$ Barbara Sgorbini, ${ }^{2}$ Cecilia Cagliero, ${ }^{2}$ Carlo Bicchi, ${ }^{2}$ \\ Jordi Eras, ${ }^{1}$ and Mercè Balcells ${ }^{1}$ \\ ${ }^{1}$ Departament de Química, Universitat de Lleida-Agrotecnio Center, Avda. Alcalde Rovira Roure 191, 25198 Lleida, Spain \\ ${ }^{2}$ Dipartimento di Scienza e Tecnologia del Farmaco, Università degli Studi di Torino, Via P. Giuria 9, 10125 Torino, Italy \\ Correspondence should be addressed to Mercè Balcells; balcells@quimica.udl.cat
}

Received 22 January 2017; Accepted 23 March 2017; Published 12 April 2017

Academic Editor: Ioannis G. Roussis

Copyright ( 2017 Alexis Marsol-Vall et al. This is an open access article distributed under the Creative Commons Attribution License, which permits unrestricted use, distribution, and reproduction in any medium, provided the original work is properly cited.

\begin{abstract}
Fruit and vegetable fibres resulting as by-products of the fruit juice industry have won popularity because they can be valorised as food ingredients. In this regard, bioactive compounds have already been studied but little attention has been paid to their remaining volatiles. Considering all the samples, 57 volatiles were identified. Composition greatly differed between citrus and noncitrus fibres. The former presented over $90 \%$ of terpenoids, with limonene being the most abundant and ranging from $52.7 \%$ in lemon to $94.0 \%$ in tangerine flesh. Noncitrus fibres showed more variable compositions, with the predominant classes being aldehydes in apple (57.5\%) and peach (69.7\%), esters (54.0\%) in pear, and terpenoids (35.3\%) in carrot fibres. In addition, enantioselective analysis of some of the chiral terpenoids present in the fibre revealed that the enantiomeric ratio for selected compounds was similar to the corresponding volatile composition of raw fruits and vegetables and some derivatives, with the exception of terpinen-4-ol and $\alpha$-terpineol, which showed variation, probably due to the drying process. The processing to which fruit residues were submitted produced fibres with low volatile content for noncitrus products. Otherwise, citrus fibres analysed still presented a high volatile composition when compared with noncitrus ones.
\end{abstract}

\section{Introduction}

The recovery, recycling, and upgrading of waste material are particularly relevant in the food and food processing industry, in which waste, effluents, residues, and by-products can be reclaimed and often turned into useful higher-valueadded products [1]. The food industry can take advantage of the physicochemical properties of these products to improve the viscosity, texture, sensory characteristics, and shelf life of final products. Hence, fibre-rich by-products can serve as inexpensive, noncaloric bulking agents for the partial replacement of flour, fat, or sugar. They can also be used to enhance water and oil retention and to improve emulsion or the oxidative stability of food products $[2,3]$. Due to the increasing importance of these products in the food industry, several studies have addressed their characterisation, either of physicochemical properties $[4,5]$ or of composition in bioactive compounds [6,7]. Although aroma is a key sensory attribute to consider when using a product in the food industry, to the best of our knowledge, only one study has been devoted to the volatile composition of one by-product, namely, apple [8].

Gas chromatography-mass spectrometry (GC-MS) is the ideal analysis technique to analyse the composition of the volatile fraction of fibres derived from the juice industry since GC offers high separation power and MS useful spectra for compound identification and quantification. On the other hand, solid-phase microextraction (SPME), introduced by Arthur and Pawliszyn [9] and extended to headspace (HS) sampling by Zhang and Pawliszyn [10], is a reliable routine technique to sample the volatile fraction of complex matrices because of its simplicity, sensitivity, possibility of automation, 
and lack of solvent use. Enantioselective-gas chromatography (Es-GC) analysis using cyclodextrins as chiral selectors has been applied in the quality control of several fruits and beverages to detect adulteration with synthetic flavours [11, 12] and to monitor the possible effects of orange juice thermal processing on the enantiomeric ratio of several terpenic components [13]. Therefore, the study of the enantiomeric ratio of diagnostic chiral volatile compounds present in fibre samples can offer further useful information for their comparison.

The aim of this work was to characterize the volatile fraction of several fruit and vegetable matrices which play an important role in juice producing industries and are expected to be further applied as food ingredients resulting in the valorisation of what initially was considered as a residue. The fibres analysed included apple, pear, peach, carrot, lemon flesh, orange flesh, orange peel, tangerine flesh, and tangerine peel. These fibres were obtained from several batches of processed industrial raw material from a currently operative juice production line. Moreover, the composition of these fruit-derived by-products has been compared to the results of several existing studies reporting the volatile composition of raw fruits and juices to assess the differences between fruits and related fibres resulting from processing. In addition, an enantioselective analysis of some of the chiral terpenes present in the fruit fibre samples was performed and their enantiomeric ratios were compared to those reported in the literature, in order to determine possible variations caused by the processing to which the fruit was subjected in the juice industry.

\section{Materials and Methods}

2.1. Samples. A local juice company (Indulleida S.A., Alguaire (Lleida), Spain) provided fibre samples from apple (6), pear (5), peach (5), carrot (1), lemon flesh (5), orange flesh (6), orange peel (1), tangerine flesh (1), and tangerine peel (1). All samples were industrially processed according to the scheme shown in Figure 1. This procedure involved washing with potable water followed by wet milling. Next, samples were submitted to a drying step and milled again. Finally, fibres were sieved to achieve a homogenous texture and sacked.

2.2. Headspace Solid-Phase Microextraction (HS-SPME). Between $100 \mathrm{mg}$ and $1 \mathrm{~g}$, depending on the sample, of fruit fibre was homogenised in $10 \mathrm{~mL}$ of $\mathrm{H}_{2} \mathrm{O}$ saturated with $\mathrm{NaCl}$ and placed in a $20 \mathrm{~mL}$ headspace vial.

HS-SPME of the volatile fraction was carried out with a $2 \mathrm{~cm}$ SPME fibre CAR/PDMS/DVB (carboxen/polydimethylsiloxane/divinylbenzene; $50 / 30 \mu \mathrm{m}$ ) from Supelco (Bellefonte, PA, USA) at $50^{\circ} \mathrm{C}$ for $45 \mathrm{~min}$ using agitation of $250 \mathrm{rpm}$.

2.3. Gas Chromatography-Mass Spectrometry (GC-MS) Anal$y$ sis. GC-MS analyses were performed with an MPS-2 multipurpose sampler (Gerstel, Mülheim an der Ruhr, Germany) assembled on an Agilent 6890 (Palo Alto, CA, USA) gas chromatograph coupled to an Agilent 5973N Quadrupole Mass Selective Detector (MSD). The SPME fibre was desorbed into the injection port at $250^{\circ} \mathrm{C}$ in split mode (ratio
1:5) for $5 \mathrm{~min}$. Compounds were separated with a MEGA5 column $(30 \mathrm{~m} \times 0.25 \mathrm{~mm}$ i.d. $\times 0.25 \mu \mathrm{m}$ film thickness $)$ from Mega (Legnano, MI, Italy) using helium as carrier gas $\left(1 \mathrm{~mL} \cdot \mathrm{min}^{-1}\right)$. The oven was temperature-programmed from $50^{\circ} \mathrm{C}$ (held for $1 \mathrm{~min}$ ) to $160^{\circ} \mathrm{C}$ at $3^{\circ} \mathrm{C} \cdot \mathrm{min}^{-1}$ and then to $250^{\circ} \mathrm{C}$ at $20^{\circ} \mathrm{C} \cdot \mathrm{min}^{-1}$ (held for $2 \mathrm{~min}$ ). Mass spectra were recorded in electron impact (EI) mode at $70 \mathrm{eV}$ within the mass range $35-350 \mathrm{~m} / z$. The transfer line, the ionization source, and the quadrupole were thermostated at 280,230 , and $150^{\circ} \mathrm{C}$, respectively. Acquisition was done using MSD ChemStation software (Agilent Technologies, Palo Alto, CA, USA). All analyses were performed in duplicate.

Volatile compound identification was based on the comparison of experimental spectra with those of the Wiley 7 and Essential Oils mass spectral libraries (Wiley, New York, NY, USA) and was further confirmed by linear retention indices (LRI) calculated using an $n$-alkane mixture (C9:C30) [14], which were compared to those reported in Adams database [15] and Nist WebBook [16].

Peak areas calculated from total ion current (TIC) for each compound were normalised by in-fibre internal standardisation [17] as follows: $5 \mu \mathrm{L}$ of $50 \mathrm{ppm}$ solution of tridecane in dibutyl phthalate was sampled for $15 \mathrm{~min}$ at $50^{\circ} \mathrm{C}$ and the relative abundance data (percentage on total volatile composition) were then calculated. This procedure was adopted to normalise the analytical deviation produced by variations in the performance of fibre and instrumentation [17].

2.4. Enantioselective-Gas Chromatography (Es-GC) Analysis. Fruit fibres were manually sampled using the same conditions as described in Section 2.2. The analyses were carried out on a Shimadzu GC-2010 system coupled to a FID detector and controlled with Shimadzu GC Solution 2.30.00 software (Shimadzu, MI, Italy).

The SPME fibre was desorbed into the injection port at $220^{\circ} \mathrm{C}$ in split mode (ratio 1:5) for $5 \mathrm{~min}$. Analyses were carried out on columns coated with $30 \%$ 2,3-di-O-ethyl-6$O$-tert-butyldimethylsilyl- $\beta$-cyclodextrin (diEt-CD) diluted in PS-086 and 30\% 2,6-dimethyl-3-O-pentyl- $\beta$-cyclodextrin (Pentyl-CD) diluted in PS-086, both from Mega (Legnano, MI, Italy), using hydrogen as carrier gas $\left(1.25 \mathrm{~mL} \cdot \mathrm{min}^{-1}\right)$. The oven was temperature-programmed from $50^{\circ} \mathrm{C}$ to $127^{\circ} \mathrm{C}$ at $1.87^{\circ} \mathrm{C} \cdot \mathrm{min}^{-1}$ and then to $220^{\circ} \mathrm{C}$ at $15^{\circ} \mathrm{C} \cdot \mathrm{min}^{-1}$ (held for $1 \mathrm{~min})$. The chromatographic conditions were selected on the basis of the conditions used for the construction of the dedicated chiral library [18] and translated using the GC Method Translator Software (Agilent). LRI were calculated using a mixture of $n$-alkanes $(\mathrm{C} 9: \mathrm{C} 30)$. The elution order of each enantiomer was assigned using a dedicated chiral library of racemic standards available in the laboratory [18].

\section{Results and Discussion}

3.1. Analysis of the Volatile Fraction of Fruit Fibres. The HSSPME-GC-MS method described above was used to analyse the volatile fraction of nine fruit fibres derived from processed industrial raw materials obtained from a juice 


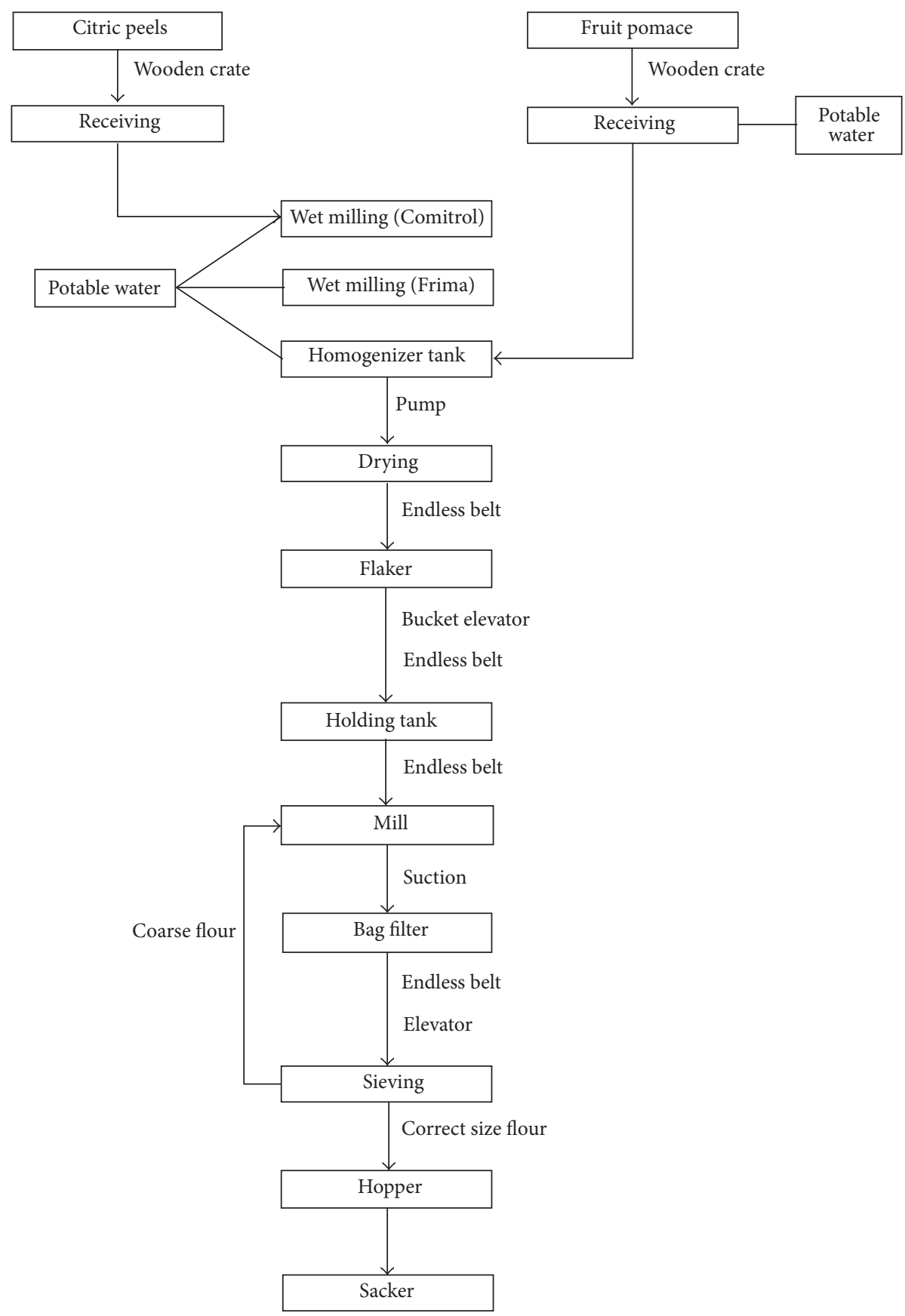

FIGURE 1: Schematics of the production process to obtain the analysed fruit fibres from residues of the juice industry.

production line. Volatiles were identified through their LRI and mass spectral data. As expected, the profile of the chromatograms revealed a high similarity between the citrus samples, namely, orange, orange peel, tangerine, tangerine peel, and lemon. On the other hand, the volatile fraction of apple, pear, peach, and carrot samples was relatively poor. Figure 2 shows the HS-SPME-GC-MS profile corresponding to lemon fibre. Peach and lemon fibres were used to evaluate the repeatability of the method. Five replicates were analysed for each fibre on various days, resulting in a satisfactory $\%$ RSD $<11 \%$ for both fibres.
3.2. Volatile Composition of Citrus Fibres. The volatile composition of citrus fibres (Table 1) consisted mainly of terpenoids, especially limonene, which accounted for about $52.7 \%$ of the total volatile fraction in lemon and over $90 \%$ in orange and tangerine fibres. Although limonene was the predominant volatile compound, all samples showed relatively high percentages of a large number of other terpenoids. For instance, lemon fibre contained, among others, $13.7 \%$ p-cymene, $7.4 \% \gamma$-terpinene, $5.1 \% \alpha$-terpinolene, $4.7 \% \alpha$ terpineol, and several other compounds at lower percentages. 


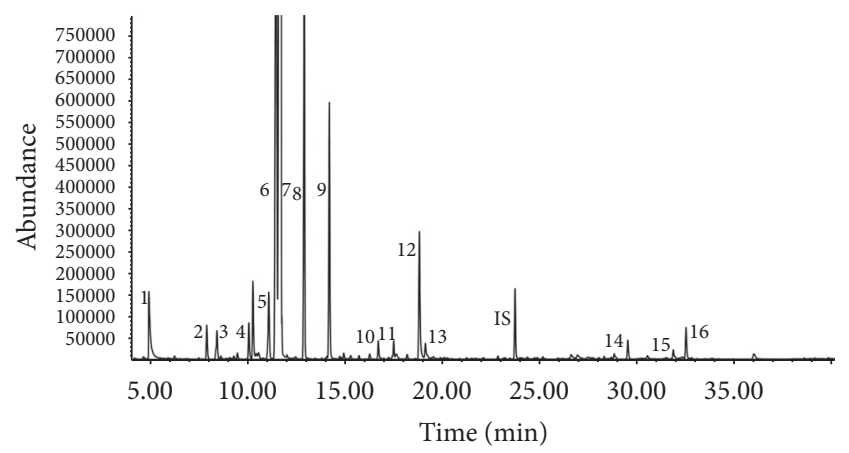

FIgure 2: HS-SPME-GC-MS profile of a lemon flesh sample. Peak identification: (1) furfural, (2) $\alpha$-pinene, (3) $\alpha$-fenchene + camphene, (4) myrcene, (5) $\alpha$-terpinene, (6) $p$-cymene, (7) limonene, (8) $\gamma$ terpinene, (9) $\alpha$-terpinolene, (10) cis- $\beta$-terpineol, (11) terpinen-4ol, (12) $\alpha$-terpineol, (13) $\gamma$-terpineol, (14) trans- $\alpha$-bergamotene, (15) valencene, and (16) $\beta$-bisabolene.

Aldehydes accounted for $8.5 \%$ of the total volatile composition in lemon fibre, the most abundant of them being furfural, which probably derived from the decomposition of sugars on the fibre. Other aldehydes found in lemon samples were heptanal, hexanal, (E)-2-heptenal, benzaldehyde, and nonanal. Ketones, esters, and alcohols were also found in the samples but at low concentrations (in all cases below 1\%). Of note, the composition of the volatile fraction of citrus fibre is qualitatively comparable to those of raw fruits, essential oils [20], and juices [21-23].

Orange and tangerine flesh samples presented almost the same volatile composition, again showing a profile clearly dominated by terpenes ( 99.4 and $98.9 \%$ of total volatiles with a high predominance of limonene 92.3 and $94.0 \%$, resp.). The same behaviour was observed for orange and tangerine peel fibres, which showed the same individual volatiles and similar percentages of the same. Moreover, the orange and tangerine peel samples presented a greater variety of compounds, including some terpenic acetates (e.g., $\alpha$ terpinyl, citronellyl, and neryl acetate) and sesquiterpenoids, such as $\beta$-cubebene, alloaromadendrene, $\alpha$-caryophyllene, and the cyclic monoterpene $\alpha-(E)$-ionone, which were not detected in the flesh samples.

On the basis of the total area, the residual amount of volatile fraction in tangerine and orange peel was higher than that in the corresponding flesh, the latter being much higher than the amount found in lemon. This finding is in agreement with previous studies that report a major content of volatile compounds, especially of limonene, in orange peel compared to orange flesh $[24,25]$.

3.3. Volatile Composition of Noncitrus Fruit and Carrot. Unlike citrus fibre, apple, pear, peach, and carrot fibres showed a volatile composition with a lower percent of terpenoids (Table 2). In this case, the analyses revealed that the most abundant group of compounds in apple fibre was that of aldehydes (57.5\%), the main ones being hexanal (19.7\%), benzaldehyde (15.6\%), and (E)-2-heptenal (14.9\%). Esters accounted for $16.3 \%$ of the volatile fraction, with butyl isobutyrate $(12.1 \%)$ as the major component. Also, ketones were present in a considerable amount (11.6\%), while terpenoids accounted for $11.4 \%$.

The volatile fraction composition of apple fibre was severely affected during fibre production if compared to that of raw fruit described in several publications [26, 27]. This observation could be attributed to the thermal treatment used during the juicing process. Former studies report ethyl esters, higher alcohols, and $\alpha$-farnesene as the main components rather than aldehydes.

Pear fibre contained esters as the main constituents (54.0\%), with hexyl acetate being the most abundant (49.1\%). Volatile aldehydes accounted for a substantial fraction of these samples (32.8\%), the most abundant being furfural (15.2\%), followed by hexanal, (E)-2-heptenal, benzaldehyde, octanal, and heptanal. Other groups of compounds, such as alcohols, ketones, ethers, and terpenoids, were present in minor percentage. In this case, the volatile fraction of pear fibre is qualitatively comparable to that of raw fruits reported in previous studies [28], where esters were found to be the main fraction. Riu-Aumatell et al. [29] reported hexyl acetate as one of the compounds consistently found in 11 commercial samples of pear juice.

Peach fibre also showed a high proportion of aldehydes $(69.7 \%)$, where furfural $(43.2 \%)$ and hexanal $(17.4 \%)$ prevailed, together with heptanal, benzaldehyde, $(E)$-2-heptenal, and nonanal in percentages ranging on average between 1.4 and $2.6 \%$. For these samples, terpenoids accounted for $22.4 \%$ of the volatile fraction. The main terpenoids found in peach fibre were mainly $\alpha$-terpineol, limonene, and $\alpha$-phellandrene. Ketones and ethers were present in lower percentages, 6.1 and $1.6 \%$, respectively. The volatile fraction of the peach fibres contained several terpenoids at a percentage comparable to that of raw fruits [29], while lactones, key markers of peach aroma [30, 31], were not detected.

The volatile fraction of carrot fibre contained terpenoids as the main group of compounds (35.3\%). Other studies have reported that these compounds account for $97 \%$ of the total volatile fraction of fresh carrot samples [32]; the lower percent found in the analysed sample could be explained by the loss of volatiles during the washing and drying treatment applied during industrial fibre processing. The most abundant components of carrot fibre were $\alpha$ - and $\beta$-ionone, at 8.1 and $9.8 \%$, respectively. The correlation between carotenoid degradation caused by processing and the production of degradative terpenes such as ionones has been described by Kanasawud and Crouzet [33]. Aldehydes accounted for $32.8 \%$ of total volatile composition of this fibre, with hexanal at $20.3 \%$ and ketones at $16.1 \%$. These included 1-octen-3-one, 6-methyl-5-hepten2-one, 2-methyl-3-octanone, 2,2,6-trimethylcyclohexanone, and 2,3,4-trimethylcyclohexen-1-one, all present at between 1.9 and $6.5 \%$. Esters, ethers, and alcohols were present at 5.1, 1.8 , and $1.3 \%$, respectively. On the basis of the total area, the volatile fraction of noncitrus fibre was about 10 -fold lower than citrus flesh fibre and almost 100-fold lower than citrus peel fibre, that is, the matrices containing the highest amount of volatile compounds. 
TABLE 1: Average relative percentage of volatile contents and their distribution ranges in different production batches (in parenthesis) of citrus fibres, as determined by HS-SPME-GC-MS analysis.

\begin{tabular}{|c|c|c|c|c|c|c|c|}
\hline & LRI (exp.) & LRI (ref.) & Lemon fibre & Orange flesh fibre & $\begin{array}{l}\text { Tangerine flesh } \\
\text { fibre }\end{array}$ & $\begin{array}{l}\text { Orange peel } \\
\text { fibre }\end{array}$ & $\begin{array}{l}\text { Tangerine peel } \\
\text { fibre }\end{array}$ \\
\hline & & & Mean $(n=5)$ & Mean $(n=6)$ & Mean $(n=1)$ & Mean $(n=1)$ & Mean $(n=1)$ \\
\hline \multicolumn{8}{|l|}{ Aldehydes } \\
\hline Hexanal & & & $0.2(0.1-0.4)$ & 0.1 (traces- -0.2$)$ & 0.4 & Traces & Traces \\
\hline Furfural & & & $7.7(4.6-13.0)$ & Traces & 0.1 & & \\
\hline Heptanal & 902 & 905 & Traces & Traces & 0.1 & & \\
\hline (E)-2-Heptenal & 959 & 957 & $0.2(0.1-0.4)$ & 0.1 (traces -0.1$)$ & Traces & Traces & Traces \\
\hline Benzaldehyde & 963 & 961 & $0.1(0.1-0.1)$ & 0.1 (traces -0.2$)$ & 0.3 & & \\
\hline Nonanal & 1106 & 1103 & $0.3(0.2-0.4)$ & 0.1 (traces-0.1) & 0.2 & Traces & Traces \\
\hline Decanal & 1207 & 1205 & & 0.1 (traces- -0.2$)$ & 0.1 & 0.2 & Traces \\
\hline Subtotal & & & 8.5 & 0.5 & 1.2 & 0.2 & 0.1 \\
\hline \multicolumn{8}{|l|}{ Ketones } \\
\hline 6-Methyl-5-hepten-2-one & 989 & 985 & $0.1(0.1-0.1)$ & & & & \\
\hline Subtotal & & & 0.1 & 0.0 & 0.0 & 0.0 & 0.0 \\
\hline \multicolumn{8}{|l|}{ Esters } \\
\hline Butyl isobutyrate & 956 & 954 & $0.3(0.1-0.5)$ & 0.1 (traces- -0.1 ) & 0.1 & & \\
\hline Hexyl butanoate & 1194 & 1190 & & & & Traces & Traces \\
\hline Octyl acetate & 1216 & 1215 & & Traces & 0.1 & 0.1 & 0.1 \\
\hline Butyl benzoate & 1378 & 1376 & $0.3(0.2-0.4)$ & & & & \\
\hline Subtotal & & & 0.6 & 0.1 & 0.2 & 0.1 & \\
\hline \multicolumn{8}{|l|}{ Alcohols } \\
\hline 1-Heptanol & 973 & 970 & 0.1 (traces- 0.2 ) & & & & \\
\hline Subtotal & & & 0.1 & 0.0 & 0.0 & 0.1 & 0.1 \\
\hline \multicolumn{8}{|l|}{ Terpenoids } \\
\hline$\alpha$-Thujene & 930 & 931 & & & & 0.1 & 0.1 \\
\hline$\alpha$-Pinene & 937 & 939 & $0.7(0.4-1.2)$ & $0.4(0.2-0.7)$ & 0.4 & 0.7 & 0.9 \\
\hline$\alpha$-Fenchene ${ }^{1}$ & 950 & 951 & $0.8(0.6-1.3)$ & & & & \\
\hline$\beta$-Pinene ${ }^{2}$ & 978 & 980 & 0.1 (traces -0.2 ) & 0.1 (traces-0.1) & Traces & 0.5 & 0.2 \\
\hline Myrcene & 996 & 991 & $0.6(0.4-1.4)$ & $2.0(1.4-3.4)$ & 1.8 & 3.6 & 3.6 \\
\hline$\alpha$-Phellandrene & 1005 & 1005 & $0.2(0.1-0.4)$ & & & & \\
\hline$\delta$-3-Carene & 1011 & 1011 & & $0.2(0.1-0.3)$ & 0.1 & 0.2 & Traces \\
\hline$\alpha$-Terpinene & 1017 & 1016 & $1.2(0.5-3.6)$ & $0.1(0.1-0.2)$ & 0.1 & Traces & Traces \\
\hline p-Cymene & 1018 & 1018 & $13.7(8.9-21.7)$ & $0.6(0.3-1.7)$ & Traces & 0.2 & 0.1 \\
\hline Limonene & 1027 & 1026 & $\begin{array}{c}52.7 \\
(28.3-61.3)\end{array}$ & $92.3(88.8-93.6)$ & 94.0 & 92.2 & 90.4 \\
\hline$\beta$-Ocimene & 1031 & 1031 & & 0.1 (traces- 0.2 ) & 0.1 & 0.2 & 0.3 \\
\hline$\gamma$-Terpinene & 1053 & 1050 & $7.4(4.0-15.1)$ & $0.5(0.3-1.0)$ & 0.4 & 0.4 & 2.6 \\
\hline$\alpha$-Terpinolene & 1062 & 1062 & $5.1(3.7-9.3)$ & $0.2(0.2-0.3)$ & 0.3 & 0.3 & 0.3 \\
\hline Linalool & 1100 & 1098 & $0.1(0.1-0.1)$ & 0.1 (traces-0.1) & Traces & Traces & Traces \\
\hline $1,3,8$ - $p$-Menthatriene & 1113 & 1111 & & $\begin{array}{c}\text { Traces } \\
\text { (traces-0.1) }\end{array}$ & Traces & Traces & Traces \\
\hline endo-Fenchol & 1114 & 1112 & $0.2(0.1-0.2)$ & & & & \\
\hline Unknown $(\mathrm{MW}=172)$ & 1124 & & $0.1(0.1-0.2)$ & Traces & Traces & Traces & Traces \\
\hline Terpinen-1-ol & 1137 & 1134 & $0.1(0.1-0.3)$ & Traces & 0.2 & Traces & Traces \\
\hline
\end{tabular}


TABle 1: Continued.

\begin{tabular}{|c|c|c|c|c|c|c|c|}
\hline & LRI (exp.) & LRI (ref.) & Lemon fibre & Orange flesh fibre & $\begin{array}{l}\text { Tangerine flesh } \\
\text { fibre }\end{array}$ & $\begin{array}{l}\text { Orange peel } \\
\text { fibre }\end{array}$ & $\begin{array}{l}\text { Tangerine peel } \\
\text { fibre }\end{array}$ \\
\hline & & & Mean $(n=5)$ & Mean $(n=6)$ & Mean $(n=1)$ & Mean $(n=1)$ & $\operatorname{Mean}(n=1)$ \\
\hline cis- $\beta$-Terpineol & 1147 & 1144 & $0.5(0.4-0.8)$ & Traces & Traces & & \\
\hline Borneol & 1163 & 1165 & $0.5(0.4-0.6)$ & & & & \\
\hline 4-Terpineol & 1178 & 1177 & $0.2(0.1-0.2)$ & $0.1(0.1-0.3)$ & Traces & 0.1 & 0.1 \\
\hline$\alpha$-Terpineol & 1191 & 1189 & $4.7(3.2-6.6)$ & $0.3(0.1-0.5)$ & 0.2 & Traces & Traces \\
\hline$\gamma$-Terpineol & 1196 & 1192 & $0.4(0.2-0.9)$ & & & & \\
\hline Safranal & 1199 & 1201 & & Traces & 0.1 & Traces & Traces \\
\hline Carvone & 1250 & 1245 & & Traces & 0.1 & Traces & Traces \\
\hline$\alpha$-Terpinyl acetate & 1356 & 1350 & & & & 0.1 & Traces \\
\hline Citronellyl acetate & 1361 & 1360 & & & & Traces & 0.1 \\
\hline Neryl acetate & 1371 & 1368 & & & & Traces & 0.1 \\
\hline$\alpha$-Copaene & 1379 & 1376 & & $0.2(0.1-0.3)$ & 0.3 & 0.1 & 0.1 \\
\hline$\beta$-Elemene & 1393 & 1391 & & & & 0.1 & 0.1 \\
\hline$(E)-\beta$-Caryophyllene & 1420 & 1418 & & 0.1 (traces- -0.1$)$ & Traces & & \\
\hline$\alpha$-(E)-Ionone & 1428 & 1426 & & & & 0.1 & Traces \\
\hline$\beta$-Cubebene & 1430 & 1434 & & & & Traces & Traces \\
\hline trans- $\alpha$-Bergamotene & 1437 & 1438 & $0.4(0.2-0.8)$ & & & & \\
\hline Alloaromadendrene & 1452 & 1455 & & & & Traces & Traces \\
\hline$\alpha$-Caryophyllene & 1453 & 1455 & & & & Traces & Traces \\
\hline$\beta$-Farnesene & 1459 & 1458 & & $0.2(0.1-0.4)$ & & Traces & Traces \\
\hline$\beta$-Ionone & 1488 & 1485 & & & & & \\
\hline Valencene & 1493 & 1491 & $0.5(0.2-0.7)$ & $1.6(0.1-4.1)$ & 0.1 & 0.8 & 0.7 \\
\hline$\beta$-Bisabolene & 1510 & 1509 & & 0.1 (traces -0.4$)$ & 0.5 & Traces & 0.1 \\
\hline$\alpha$-Farnesene & 1511 & 1508 & & & 0.1 & & \\
\hline 7-epi- $\alpha$-Selinene & 1516 & 1517 & & 0.1 (traces- 0.2 ) & Traces & Traces & Traces \\
\hline$\delta$-Cadinene & 1525 & 1524 & & 0.1 (traces -0.1$)$ & 0.1 & 0.1 & 0.1 \\
\hline$\gamma$-Bisabolene & 1534 & 1533 & $0.6(0.3-1.4)$ & & & & \\
\hline Total (\%) & & & 91.0 & 99.4 & 98.9 & 99.8 & 99.9 \\
\hline Total normalised area & & & $30.6 \pm 9.7$ & $68.1 \pm 42.7$ & 65.1 & 408.7 & 353.3 \\
\hline
\end{tabular}

${ }^{1}$ In lemon fibre, area includes camphene as a result of coelution.

${ }^{2}$ In orange and tangerine peel fibres, area includes sabinene as a result of coelution.

The term "traces" indicates area percentage $<0.05 \%$.

3.4. Es-GC Analysis of Chiral Markers in Fruit Fibre Samples. Here, we sought to study some of the chiral markers present in the fruit fibre samples in order to assess whether the processing (which includes thermal treatment) affects the enantiomeric ratio (ER), that is, with an increase of racemisation of some chiral compounds. HS sampling by SPME was therefore applied in the same optimised conditions as previously described in Section 3.1, in combination with Es-GC with cyclodextrin derivatives as chiral selectors. The ER of the selected chiral markers was compared to those previously reported in the literature for samples of the same fruit origin, namely, fresh fruits, juices, or essential oils, when available.

Only five chiral markers could be selected ( $\alpha$-pinene, $\beta$ pinene, limonene, $\alpha$-terpineol, and $\alpha$-ionone) for noncitrus fibres due to the low abundance of volatile compounds, as reported in Section 3.3. On the other hand, for citrus samples, chiral marker selection was limited by the presence of coelution. diEt- $\beta$-CD and Pentyl- $\beta$-CD columns were used to achieve reliable separation of a higher number of compounds. Moreover, pure standard mixtures of racemic terpenes were injected under the same Es-GC conditions to facilitate enantiomer identification.

3.5. Es-GC Analysis of Selected Chiral Markers in Noncitrus Fruit and Carrot Fibres. Very few chiral compounds were analysed in noncitrus fibres. However, the ER variability of chiral compounds among samples of each fruit was low (Table 3). A high ER was measured for the $R$-limonene enantiomer (>99\%). $\alpha$-Pinene and $\alpha$-ionone in carrot fibre were present with a higher ER in favour of the $S$-enantiomer, while $\beta$-pinene in pear was present in a racemic form. $\alpha$ Terpineol was found in all samples, with a higher abundance 
TABLE 2: Average relative percentage of volatile compounds present and their distribution ranges in different production batches (in parenthesis) of apple, pear, peach, and carrot fibres, as determined by HS-SPME-GC-MS analysis.

\begin{tabular}{|c|c|c|c|c|c|c|}
\hline & LRI (exp.) & LRI (ref.) & $\begin{array}{c}\text { Apple fibre } \\
\text { Mean }(n=6)\end{array}$ & $\begin{array}{c}\text { Pear fibre } \\
\text { Mean }(n=5)\end{array}$ & $\begin{array}{c}\text { Peach fibre } \\
\text { Mean }(n=5)\end{array}$ & $\begin{array}{c}\text { Carrot fibre } \\
\text { Mean }(n=1)\end{array}$ \\
\hline \multicolumn{7}{|l|}{ Hydrocarbons } \\
\hline 2,4-Dimethyl-1-heptene & & & $2.1(0.9-4.4)$ & 0.1 (traces -0.3 ) & & \\
\hline 4-Methyl octane & & & 0.5 (traces-1.3) & & & 3.0 \\
\hline Subtotal & & & 2.6 & 0.1 & 0.0 & 3.0 \\
\hline \multicolumn{7}{|l|}{ Aldehydes } \\
\hline Hexanal & & & $19.7(9.2-27.7)$ & $7.4(5.2-9.0)$ & $17.4(10.6-21.3)$ & 20.3 \\
\hline Furfural & & & $2.6(1.8-3.4)$ & $15.2(9.0-21.1)$ & $43.2(38.8-43.3)$ & 1.6 \\
\hline Heptanal & 902 & 905 & $1.3(1.0-1.7)$ & $0.7(0.5-0.9)$ & $1.4(0.5-1.7)$ & 2.6 \\
\hline (E)-2-heptenal & 959 & 957 & $14.9(12.1-20.2)$ & $3.9(1.5-6.4)$ & $2.6(1.8-4.1)$ & 3.6 \\
\hline Benzaldehyde & 963 & 961 & $15.6(11.6-22.4)$ & $3.6(0.9-6.3)$ & 2.5 (traces-3.6) & 1.3 \\
\hline Pentylfuran & 993 & 996 & Traces & & & \\
\hline Octanal & 1004 & 1001 & $1.7(1.0-3.3)$ & $2.0(1.34-2.41)$ & & \\
\hline Nonanal & 1106 & 1103 & $1.7(1.2-2.2)$ & & $2.6($ traces -4.1$)$ & 3.0 \\
\hline Decanal & 1207 & 1205 & & & & 0.4 \\
\hline Subtotal & & & 57.5 & 32.8 & 69.7 & 32.8 \\
\hline \multicolumn{7}{|l|}{ Ketones } \\
\hline 1-Octen-3-one & 980 & 980 & $6.3(3.9-9.2)$ & $3.1(0.9-4.4)$ & $1.7(1.0-3.0)$ & 4.7 \\
\hline 2-Methyl-3-octanone & 986 & 985 & & & 0.7 (traces-1.8) & \\
\hline 6-Methyl-5-hepten-2-one & 989 & 985 & $5.3(2.7-7.7)$ & $2.7(1.9-3.7)$ & $3.7(2.50-4.8)$ & 3.0 \\
\hline 2,2,6-Trimethylcyclohexanone & 1037 & 1036 & & & & 6.5 \\
\hline 3,4,4-Trimethylcyclohexen-1-one & 1082 & & & & & 1.9 \\
\hline Subtotal & & & 11.6 & 5.8 & 6.1 & 16.1 \\
\hline \multicolumn{7}{|l|}{ Ethers } \\
\hline Butyl ether & & & $0.7(0.4-1.0)$ & $1.0(0.4-1.4)$ & $1.6($ traces -2.2$)$ & 1.8 \\
\hline \multicolumn{7}{|l|}{ Esters } \\
\hline Butyl acetate & & & & $3.8(2.9-6.0)$ & & \\
\hline Pentyl acetate & 917 & 916 & & $1.1(0.9-1.2)$ & & \\
\hline Butyl isobutyrate & 956 & 954 & $12.1(9.5-16.6)$ & & & 0.9 \\
\hline Hexyl acetate & 1017 & 1016 & $1.5(0.5-2.7)$ & $49.1(40.4-61.2)$ & & \\
\hline Hexyl 2-methylbutanoate & 1244 & 1239 & $0.6(0.2-1.1)$ & & & \\
\hline Butyl benzoate & 1378 & 1376 & $1.3(1.1-2.0)$ & & & 4.2 \\
\hline Hexyl hexanoate & 1391 & 1386 & $0.8(0.3-2.7)$ & & & \\
\hline Subtotal & & & 16.3 & 54.0 & Traces & 5.1 \\
\hline \multicolumn{7}{|l|}{ Alcohols } \\
\hline 1-Hexanol & & & & $1.2(0.8-1.7)$ & & \\
\hline (E)-2-Cyclohexen-1-ol & 1097 & 1097 & & & & 0.9 \\
\hline 2,6-Dimethyl cyclohexanol & 1110 & 1114 & & & & 0.4 \\
\hline Subtotal & & & Traces & 1.2 & Traces & 1.3 \\
\hline \multicolumn{7}{|l|}{ Terpenoids } \\
\hline$\alpha$-Pinene & 937 & 939 & 0.2 (traces -0.5$)$ & & $0.2($ traces -0.6$)$ & 1.2 \\
\hline$\beta$-Pinene & 978 & 980 & & $1.2(0.6-2.3)$ & & \\
\hline Myrcene & 996 & 991 & & & & 0.6 \\
\hline$\alpha$-Phellandrene & 1005 & 1005 & & & $3.2(1.8-6.1)$ & \\
\hline p-Cymene & 1027 & 1026 & & & $1.1(0.3-2.0)$ & 2.7 \\
\hline Limonene & 1031 & 1031 & $3.1(0.9-3.2)$ & & $6.1(1.9-17.8)$ & \\
\hline
\end{tabular}


TABle 2: Continued.

\begin{tabular}{|c|c|c|c|c|c|c|}
\hline & LRI (exp.) & LRI (ref.) & $\begin{array}{c}\text { Apple fibre } \\
\text { Mean }(n=6)\end{array}$ & $\begin{array}{c}\text { Pear fibre } \\
\text { Mean }(n=5)\end{array}$ & $\begin{array}{c}\text { Peach fibre } \\
\text { Mean }(n=5)\end{array}$ & $\begin{array}{c}\text { Carrot fibre } \\
\text { Mean }(n=1)\end{array}$ \\
\hline$\gamma$-Terpinene & 1062 & 1062 & $5.6(4.0-8.9)$ & & $2.2(0.4-3.4)$ & \\
\hline$\alpha$-Terpinolene & 1086 & 1088 & & & & 1.3 \\
\hline Linalool & 1100 & 1098 & & & $0.9(0.5-2.0)$ & \\
\hline cis- $\beta$-Terpineol & 1147 & 1144 & $0.2(0.1-0.3)$ & & & \\
\hline 4-Terpineol & 1178 & 1177 & & & 0.4 (traces-1.3) & \\
\hline$\alpha$-Terpineol & 1191 & 1189 & $1.5(0.8-2.0)$ & $1.5(1.0-1.9)$ & $6.6(4.1-9.5)$ & 1.0 \\
\hline$\beta$-Cyclocitral & 1223 & 1222 & & & & 3.5 \\
\hline Neryl acetate & 1371 & 1368 & & & $1.1(0.6-1.5)$ & \\
\hline$(E)$ - $\beta$-Caryophyllene & 1420 & 1418 & & & & 1.9 \\
\hline$\alpha$-Ionone & 1428 & 1426 & & & & 8.1 \\
\hline Geranyl acetone & 1454 & 1455 & & & & 2.5 \\
\hline$\beta$-Ionone & 1488 & 1485 & & & & 9.8 \\
\hline Valencene & 1493 & 1491 & $0.4(0.1-0.5)$ & & $0.2($ traces -0.5$)$ & \\
\hline$\alpha$-Farnesene & 1511 & 1508 & $0.4(0.2-0.8)$ & $0.2(0.2-0.3)$ & & \\
\hline 7-epi- $\alpha$-Selinene & 1516 & 1517 & & & 0.4 (traces -2.1$)$ & \\
\hline$\gamma$-Bisabolene & 1534 & 1533 & & & & 2.7 \\
\hline Total (\%) & & & 11.4 & 2.9 & 22.4 & 35.3 \\
\hline Total normalised area & & & $7.7 \pm 2.4$ & $5.0 \pm 1.5$ & $4.1 \pm 2.3$ & 5.6 \\
\hline
\end{tabular}

The term "traces" indicates area percentage $<0.05 \%$.

TABLE 3: Chiral markers, calculated LRI, and corresponding enantiomeric ratio for noncitrus fruit fibre.

\begin{tabular}{|c|c|c|c|c|c|c|}
\hline Chiral marker & Configuration & LRI & $\begin{array}{c}\text { Apple } \\
(n=6)\end{array}$ & $\begin{array}{c}\text { Pear } \\
(n=5)\end{array}$ & $\begin{array}{l}\text { Peach } \\
(n=5)\end{array}$ & $\begin{array}{l}\text { Carrot } \\
(n=1)\end{array}$ \\
\hline \multirow{2}{*}{$\alpha$-Pinene } & $S$ & 923 & & & & 69.7 \\
\hline & $\mathrm{R}$ & 925 & & & & 30.3 \\
\hline \multirow{2}{*}{$\beta$-Pinene } & $\mathrm{R}$ & 946 & & $47.5-51.9$ & & \\
\hline & $S$ & 956 & & $52.5-48.1$ & & \\
\hline \multirow{2}{*}{ Limonene } & S & 1056 & Traces & & Traces & \\
\hline & $\mathrm{R}$ & 1072 & $>99.9$ & & $>99.9$ & \\
\hline \multirow{2}{*}{$\alpha$-Terpineol } & $\mathrm{R}$ & 1296 & $39.5-46.6$ & $40.6-41.3$ & $35.3-42.0$ & 25.2 \\
\hline & S & 1309 & $60.5-63.4$ & $59.4-58.7$ & $64.3-58.0$ & 74.8 \\
\hline \multirow{2}{*}{$\alpha$-Ionone } & $\mathrm{R}$ & 1414 & & & & 12.6 \\
\hline & S & 1424 & & & & 87.4 \\
\hline
\end{tabular}

of the S-enantiomer, ranging from 58.0 to $74.8 \%$, in all noncitrus samples.

3.6. Es-GC Analysis of Selected Chiral Markers in Citrus Fruit Fibre. ERs were calculated for eight chiral markers in lemon fibre (Table 4). The results are, in general, in good agreement with those reported for the enantiomeric composition of essential oils. An ER was observed for all the chiral markers except for linalool, which was almost in a racemic form. This result is in agreement with the literature reporting that the enantiomeric composition of linalool in lemon essential oils is highly variable depending on the cultivar and harvest period [34]. The monoterpenes $\alpha$-pinene, $\beta$-pinene, borneol, and $\alpha$-terpineol presented a higher ratio of the $S$-enantiomer while camphene and limonene gave higher ratios of the $R$ enantiomer. The ERs calculated for these compounds show in all cases the same predominance of one of the enantiomers as reported in the literature [19]. However, the ER of terpinen4-ol tended to vary as a consequence of the high temperatures applied during processing: the pretreatment of the lemon fibres at high temperatures might explain a lower ER of the $R$-enantiomer in these fibres when compared with essential oils and juices [35].

ERs were calculated for nine chiral markers in orange and tangerine fibres (Table 5). These results are generally in good agreement with the literature on citrus essential oils [19], often showing a higher ER for one of the enantiomers, as was the case for $\alpha$-pinene, camphene, limonene, linalool, and carvone. $\beta$-Pinene, as previously described, presented a high ER of $S$-enantiomer in orange and tangerine flesh fibres, while it was racemic in both peel fibres [19]. In agreement with the reported data, the drying process applied to the 
TABLE 4: Chiral markers, calculated LRI, and corresponding enantiomeric ratio for lemon fibre.

\begin{tabular}{|c|c|c|c|c|}
\hline Chiral marker & Configuration & LRI & $\begin{array}{l}\text { Lemon } \\
(n=5)\end{array}$ & Literature data [19] \\
\hline \multirow{2}{*}{$\alpha$-Pinene ${ }^{1}$} & $\mathrm{R}$ & 923 & $15.4-22.0$ & $25.5-37.8$ \\
\hline & $\mathrm{S}$ & 925 & $84.6-78.0$ & $74.5-62.2$ \\
\hline \multirow{2}{*}{ Camphene $^{1}$} & S & 920 & $72.6-80.7$ & $86.2-92.4$ \\
\hline & $\mathrm{R}$ & 933 & $27.4-19.3$ & $13.8-7.6$ \\
\hline \multirow{2}{*}{$\beta$-Pinene ${ }^{1}$} & $\mathrm{R}$ & 946 & $15.8-21.3$ & $4.2-7.0$ \\
\hline & S & 956 & $84.2-78.7$ & $95.8-93.0$ \\
\hline \multirow{2}{*}{ Limonene $^{1}$} & S & 1056 & $0.9-4.2$ & $1.0-2.6$ \\
\hline & $\mathrm{R}$ & 1072 & $99.1-95.8$ & $99.0-97.4$ \\
\hline \multirow{2}{*}{ Linalool $^{2}$} & $\mathrm{R}$ & 1212 & $38.0-49.7$ & $49.5-74.5$ \\
\hline & $S$ & 1222 & $62.0-53.3$ & $50.5-25.5$ \\
\hline \multirow{2}{*}{ Borneol $^{2}$} & S & 1307 & $84.5-91.7$ & \\
\hline & $\mathrm{R}$ & 1317 & $15.5-8.3$ & \\
\hline \multirow{2}{*}{ Terpinen-4-ol ${ }^{2}$} & S & 1319 & $30.0-43.0$ & $12.0-32.5$ \\
\hline & $\mathrm{R}$ & 1327 & $70.0-57.0$ & $88.0-67.5$ \\
\hline \multirow{2}{*}{$\alpha$-Terpineol $^{1}$} & $\mathrm{R}$ & 1296 & $11.0-18.5$ & $35.8-18.0$ \\
\hline & S & 1309 & $89.0-81.5$ & $64.2-82.0$ \\
\hline
\end{tabular}

${ }^{1}$ LRI and enantiomeric ratios calculated using a diEt-CD column.

${ }^{2}$ LRI and enantiomeric ratios calculated using a Pentyl-CD column.

TABLE 5: Chiral markers, calculated LRI, and corresponding enantiomeric ratios for orange and tangerine fibres.

\begin{tabular}{|c|c|c|c|c|c|c|c|}
\hline Chiral marker & Configuration $^{3}$ & LRI & $\begin{array}{l}\text { Orange flesh } \\
\quad(n=5)\end{array}$ & $\begin{array}{c}\text { Tangerine flesh } \\
\quad(n=1)\end{array}$ & $\begin{array}{c}\text { Orange peel } \\
\quad(n=1)\end{array}$ & $\begin{array}{c}\text { Tangerine peel } \\
\quad(n=1)\end{array}$ & Literature data [19] \\
\hline \multirow{2}{*}{$\alpha$-Pinene $^{2}$} & $\mathrm{~S}$ & 929 & $7.6-17.8$ & 13.4 & 11.7 & 14.5 & $9.9-0.6$ \\
\hline & $\mathrm{R}$ & 936 & $92.4-82.2$ & 86.6 & 88.3 & 85.5 & $90.1-99.4$ \\
\hline \multirow{2}{*}{ Camphene $^{2}$} & $S$ & 949 & & & 29.2 & 25.4 & \\
\hline & $\mathrm{R}$ & 964 & & & 70.8 & 74.6 & \\
\hline \multirow{2}{*}{$\beta$-Pinene ${ }^{2}$} & $\mathrm{R}$ & 975 & $6.5-12.6$ & 6.1 & 46.2 & 49.3 & $10.6-70.2$ \\
\hline & S & 978 & $93.5-87.4$ & 93.9 & 53.8 & 50.7 & $89.4-29.8$ \\
\hline \multirow{2}{*}{ Limonene $^{1}$} & S & 1056 & $0.6-0.8$ & 0.6 & 0.5 & 0.6 & $0.0-1.1$ \\
\hline & $\mathrm{R}$ & 1072 & $99.4-99.2$ & 99.4 & 99.5 & 99.4 & $100-98.9$ \\
\hline \multirow{2}{*}{ Linalool $^{1}$} & $\mathrm{R}$ & 1175 & $9.7-20.4$ & 16.4 & 8.1 & 11.3 & $2.2-17.9$ \\
\hline & $\mathrm{S}$ & 1190 & $90.3-79.6$ & 83.6 & 91.9 & 88.7 & $97.8-82.1$ \\
\hline \multirow{2}{*}{ Terpinen-4-ol ${ }^{2}$} & $S$ & 1319 & $42.9-51.1$ & 28.9 & 55.7 & 57.8 & $65.3-71.5$ \\
\hline & $\mathrm{R}$ & 1327 & $57.1-49.9$ & 71.1 & 44.3 & 42.1 & $34.7-28.5$ \\
\hline \multirow{2}{*}{$\alpha$-Terpineol $^{1}$} & $\mathrm{R}$ & 1296 & $30.6-42.1$ & 41.5 & 22.7 & 48.3 & $5.1-15.7$ \\
\hline & S & 1309 & $69.4-57.9$ & 58.5 & 77.3 & 51.7 & $94.9-84.3$ \\
\hline \multirow{2}{*}{ Carvone $^{2}$} & $\mathrm{R}$ & 1346 & $32.2-41.3$ & 34.9 & 30.3 & 26.5 & 40.7 \\
\hline & $S$ & 1352 & $67.8-58.7$ & 65.1 & 69.7 & 73.5 & 59.3 \\
\hline \multirow{2}{*}{$\alpha$-Terpinyl acetate ${ }^{2}$} & $\mathrm{X}$ & 1378 & & & 21.0 & 73.5 & \\
\hline & $\mathrm{Y}$ & 1381 & & & 79.2 & 26.5 & \\
\hline
\end{tabular}

${ }^{1}$ LRI and enantiomeric ratios calculated using diEt-CD column.

${ }^{2}$ LRI and enantiomeric ratios calculated using Pentyl-CD column.

${ }^{3} \mathrm{X}$ and $\mathrm{Y}$ were used to indicate that the absolute configuration of the enantiomers could not be determined.

fibres is expected to have modified the ER of terpinen-4-ol and $\alpha$-terpineol. A similar effect had already been reported for these monoterpene alcohols when citrus essential oils are obtained through distillation instead of cold pressing [19]. Finally, the ERs of $\alpha$-terpineol in orange and tangerine peel were not coincident and showed distinct behaviour.
This difference was also observed in the ER of $\alpha$-terpinyl acetate. This observation could be explained by the fact that $\alpha$-terpinyl acetate forms from $\alpha$-terpineol via acetylation. On the other hand, for tangerine peel, racemisation was observed for $\alpha$-terpineol, while $\alpha$-terpinyl acetate probably kept its original configuration. 


\section{Conclusions}

Here, we applied HS-SPME-GC-MS to study the volatile composition of nine types of fruit and vegetable fibres, namely, apple, peach, pear, orange peel and flesh, tangerine peel and flesh, lemon flesh, and carrot, derived from the juice industry. Despite being submitted to processing which involves among others washing and drying, this study shows that the volatiles remaining in the fibres cannot be neglected. In this regard, citrus fibres contained a high amount of volatile compounds, mainly monoterpenoids (limonene). Processing to obtain fruit fibres was shown to produce fibres with low volatile content for noncitrus products. Otherwise, citrus fibres analysed still presented a high volatile composition when compared with noncitrus ones. In addition, the Es-GC analyses of the chiral volatiles present in the samples revealed that, during processing, monoterpene alcohols (terpinen-4ol and $\alpha$-terpineol) tend to show a variation in their ER, probably because of the heat applied during drying.

\section{Conflicts of Interest}

The authors declare that they have no conflicts of interest.

\section{Acknowledgments}

This study was carried out within the project "Studio di Metabolite Secondari Biologicamente Attivi da Matrici di Origine Vegetale" financially supported by the Ricerca Locale (Ex 60\% 2014) of the University of Turin, Turin (Italy). Alexis Marsol-Vall acknowledges the University of Lleida (Spain) for a fellowship to stay abroad.

\section{References}

[1] G. Laufenberg, B. Kunz, and M. Nystroem, "Transformation of vegetable waste into value added products: (A) the upgrading concept; (B) practical implementations," Bioresource Technology, vol. 87, no. 2, pp. 167-198, 2003.

[2] M. Elleuch, D. Bedigian, O. Roiseux, S. Besbes, C. Blecker, and H. Attia, "Dietary fibre and fibre-rich by-products of food processing: characterisation, technological functionality and commercial applications: a review," Food Chemistry, vol. 124, no. 2, pp. 411-421, 2011.

[3] F. Figuerola, M. L. Hurtado, A. M. Estévez, I. Chiffelle, and F. Asenjo, "Fibre concentrates from apple pomace and citrus peel as potential fibre sources for food enrichment," Food Chemistry, vol. 91, no. 3, pp. 395-401, 2005.

[4] M. C. Garau, S. Simal, C. Rosselló, and A. Femenia, "Effect of air-drying temperature on physico-chemical properties of dietary fibre and antioxidant capacity of orange (Citrus aurantium v. Canoneta) by-products," Food Chemistry, vol. 104, no. 3, pp. 1014-1024, 2007.

[5] N. Grigelmo-Miguel and O. Martín-Belloso, "Comparison of dietary fibre from by-products of processing fruits and greens and from cereals," LWT_Food Science and Technology, vol. 32, no. 8, pp. 503-508, 1999.

[6] A. Delpino-Rius, J. Eras, F. Vilaró, M. Á. Cubero, M. Balcells, and R. Canela-Garayoa, "Characterisation of phenolic compounds in processed fibres from the juice industry," Food Chemistry, vol. 172, pp. 575-584, 2015.
[7] A. Schieber, P. Keller, and R. Carle, "Determination of phenolic acids and flavonoids of apple and pear by high-performance liquid chromatography," Journal of Chromatography A, vol. 910, no. 2, pp. 265-273, 2001.

[8] R. R. Madrera and B. S. Valles, "Determination of volatile compounds in apple pomace by stir bar sorptive extraction and gas chromatography-mass spectrometry (SBSE-GC-MS)," Journal of Food Science, vol. 76, no. 9, pp. C1326-C1334, 2011.

[9] C. L. Arthur and J. Pawliszyn, "Solid phase microextraction with thermal desorption using fused silica optical fibers," Analytical Chemistry, vol. 62, no. 19, pp. 2145-2148, 1990.

[10] Z. Zhang and J. Pawliszyn, "Headspace solid-phase microextraction," Analytical Chemistry, vol. 65, no. 14, pp. 1843-1852, 1993.

[11] S. E. Ebeler, G. M. Sun, M. Datta, P. Stremple, and A. K. Vickers, "Solid-phase microextraction for the enantiomeric analysis of flavors in beverages," Journal of AOAC International, vol. 84, no. 2, pp. 479-485, 2001.

[12] C. Cagliero, C. Bicchi, C. Cordero, P. Rubiolo, B. Sgorbini, and E. Liberto, "Fast headspace-enantioselective GC-mass spectrometric-multivariate statistical method for routine authentication of flavoured fruit foods," Food Chemistry, vol. 132, no. 2, pp. 1071-1079, 2012.

[13] M. L. Ruiz del Castillo, G. Flores, G. P. Blanch, and M. Herraiz, "Effect of thermal treatment during processing of orange juice on the enantiomeric distribution of chiral terpenes," Journal of Food Protection, vol. 67, no. 6, pp. 1214-1219, 2004.

[14] B. d'Acampora Zellner, C. Bicchi, P. Dugo, P. Rubiolo, G. Dugo, and L. Mondello, "Linear retention indices in gas chromatographic analysis: a review," Flavour and Fragrance Journal, vol. 23, no. 5, pp. 297-314, 2008.

[15] R. P. Adams, Identification of Essential Oil Components by Gas Chromatography/Quadrupole Mass Spectroscopy, Allured Publishing, Carol Stream, Ill, USA, 2001.

[16] National Institute of Standards and Technology, "NIST Chemistry WebBook," NIST Standard Reference Database no. 69.

[17] Y. Wang, J. O’Reilly, Y. Chen, and J. Pawliszyn, “Equilibrium in-fibre standardisation technique for solid-phase microextraction," Journal of Chromatography A, vol. 1072, no. 1, pp. 13-17, 2005.

[18] E. Liberto, C. Cagliero, B. Sgorbini et al., "Enantiomer identification in the flavour and fragrance fields by "interactive" combination of linear retention indices from enantioselective gas chromatography and mass spectrometry," Journal of Chromatography A, vol. 1195, no. 1-2, pp. 117-126, 2008.

[19] G. Dugo and L. Mondello, Citrus Oils: Composition, Advanced Analytical Techniques, Contaminants, and Biological Activity, CRC Press, Boca Raton, Fla, USA, 2010.

[20] Á. Högnadóttir and R. L. Rouseff, "Identification of aroma active compounds in orange essence oil using gas chromatography-olfactometry and gas chromatography-mass spectrometry," Journal of Chromatography A, vol. 998, no. 1-2, pp. 201-211, 2003.

[21] G. Allegrone, F. Belliardo, and P. Cabella, "Comparison of volatile concentrations in hand-squeezed juices of four different lemon varieties," Journal of Agricultural and Food Chemistry, vol. 54, no. 5, pp. 1844-1848, 2006.

[22] Y. Qiao, J. X. Bi, Y. Zhang et al., "Characterization of aroma active compounds in fruit juice and peel oil of Jinchen sweet orange fruit (Citrus sinensis (L.) Osbeck) by GC-MS and GCO," Molecules, vol. 13, no. 6, pp. 1333-1344, 2008. 
[23] T. Barboni, F. Luro, N. Chiaramonti, J.-M. Desjobert, A. Muselli, and J. Costa, "Volatile composition of hybrids Citrus juices by headspace solid-phase micro extraction/gas chromatography/mass spectrometry," Food Chemistry, vol. 116, no. 1, pp. 382390, 2009.

[24] K. Umano, Y. Hagi, and T. Shibamoto, "Volatile chemicals identified in extracts from newly hybrid citrus, dekopon (Shiranuhi mandarin Suppl. J.)," Journal of Agricultural and Food Chemistry, vol. 50, no. 19, pp. 5355-5359, 2002.

[25] A. J. Macleod, G. Macleod, and G. Subramanian, "Volatile aroma constituents of orange," Phytochemistry, vol. 27, no. 7, pp. 2185-2188, 1988.

[26] L. Ferreira, R. Perestrelo, M. Caldeira, and J. S. Câmara, "Characterization of volatile substances in apples from Rosaceae family by headspace solid-phase microextraction followed by GCqMS," Journal of Separation Science, vol. 32, no. 11, pp. 1875-1888, 2009.

[27] E. Aprea, M. L. Corollaro, E. Betta et al., "Sensory and instrumental profiling of 18 apple cultivars to investigate the relation between perceived quality and odour and flavour," Food Research International, vol. 49, no. 2, pp. 677-686, 2012.

[28] J. L. Chen, S. Yan, Z. Feng, L. Xiao, and X. S. Hu, "Changes in the volatile compounds and chemical and physical properties of Yali pear (Pyrus bertschneideri Reld) during storage," Food Chemistry, vol. 97, no. 2, pp. 248-255, 2006.

[29] M. Riu-Aumatell, M. Castellari, E. López-Tamames, S. Galassi, and S. Buxaderas, "Characterisation of volatile compounds of fruit juices and nectars by HS/SPME and GC/MS," Food Chemistry, vol. 87, no. 4, pp. 627-637, 2004.

[30] C. Derail, T. Hofmann, and P. Schieberle, "Differences in key odorants of handmade juice of yellow-flesh peaches (Prunus persica L.) Induced by the workup procedure," Journal of Agricultural and Food Chemistry, vol. 47, no. 11, pp. 4742-4745, 1999.

[31] A. Polesello, L. Di Cesare, and R. Nani, "Recupero degli aromi dagli ortofrutticoli mediante estrazione in fase solida," Industrie delle Bevande, vol. 18, pp. 93-101, 1989.

[32] C. Alasalvar, J. M. Grigor, and P. C. Quantick, "Method for the static headspace analysis of carrot volatiles," Food Chemistry, vol. 65, no. 3, pp. 391-397, 1999.

[33] P. Kanasawud and J. C. Crouzet, "Mechanism of formation of volatile compounds by thermal degradation of carotenoids in aqueous medium. I: $\beta$-Carotene degradation," Journal of Agricultural and Food Chemistry, vol. 38, no. 1, pp. 237-243, 1990.

[34] H. Casabianca, J. B. Graff, V. Faugier, F. Fleig, and C. Grenier, "Enantiomeric distribution studies of linalool and linalyl acetate: a powerful tool for authenticity control of essential oils," HRC Journal of High Resolution Chromatography, vol. 21, no. 2, pp. 107-112, 1998.

[35] L. Mondello, A. Verzera, P. Previti, F. Crispo, and G. Dugo, "Multidimensional capillary GC-GC for the analysis of complex samples. 5. Enantiomeric distribution of monoterpene hydrocarbons, monoterpene alcohols, and linalyl acetate of bergamot (Citrus bergamia Risso et Poiteau) oils," Journal of Agricultural and Food Chemistry, vol. 46, no. 10, pp. 4275-4282, 1998. 

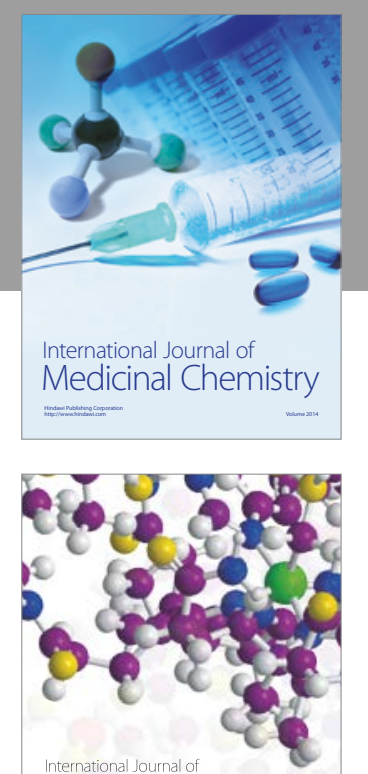

Carbohydrate Chemistry

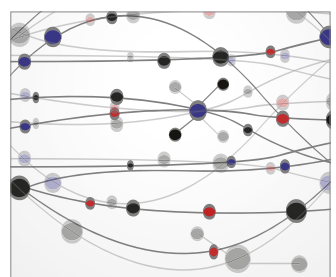

The Scientific World Journal
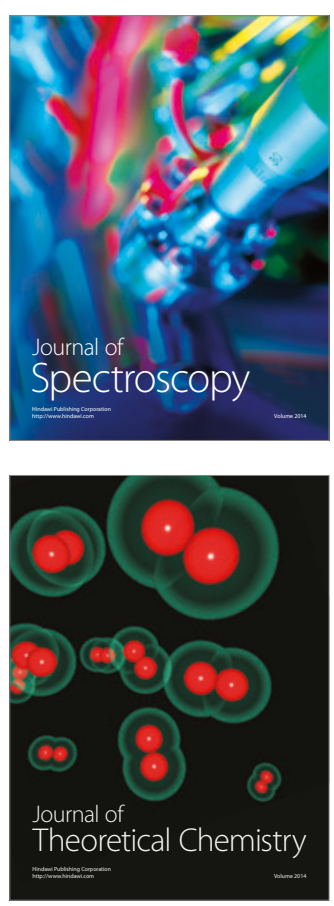
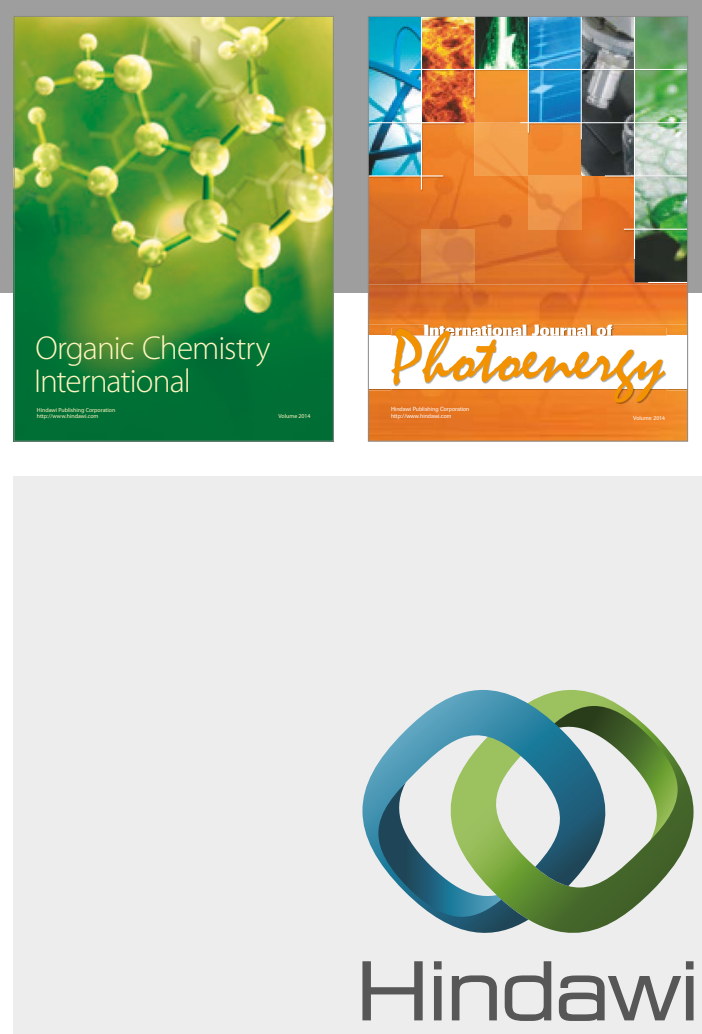

Submit your manuscripts at

https://www.hindawi.com

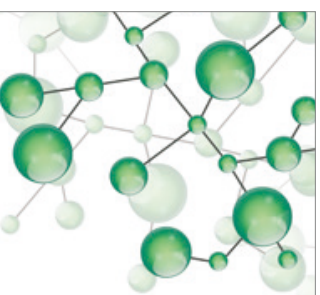

International Journal of

Inorganic Chemistry

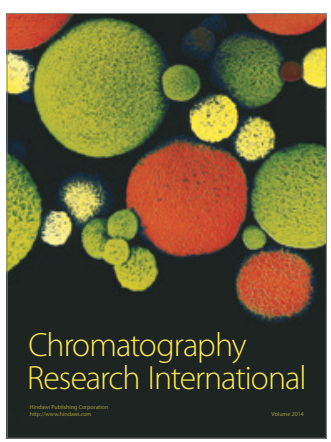

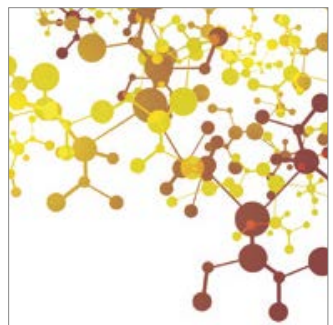

Applied Chemistry
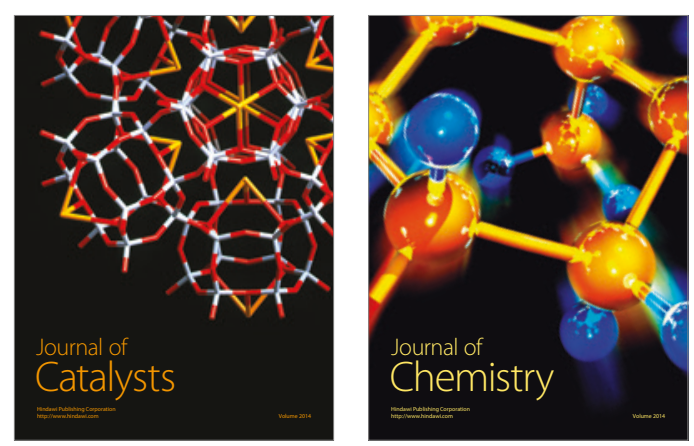
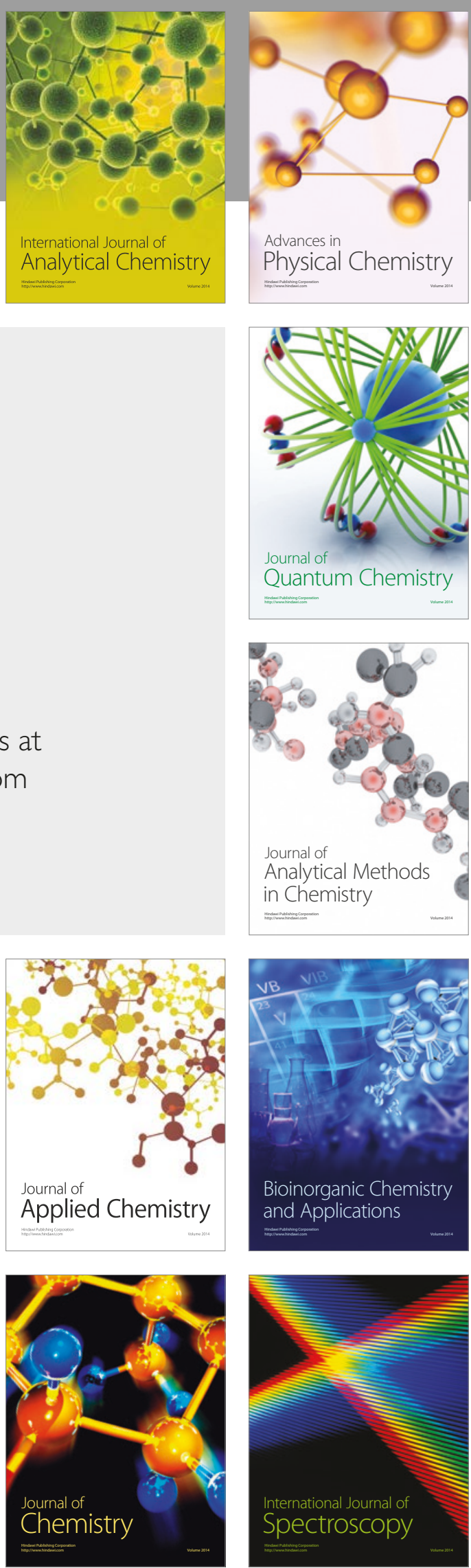